\title{
Disturbios hemodinâmicos nos vicios valvulares do coração (")
}

\author{
Jairo Ramos \\ Livre docente de clínica medica, por \\ concurso, da Faculdade de Mediclaa \\ da Universidade de S. Paulo
}

Hill, estudando a fisiologia muscular, poude demonstrar que todo músculo sujeito a um superesforço reage pelo alongamento de suas fibras afim de poder satisfazer a êste aumento de trabalho exigido.

Starling retomando os estudos de Hill sobre os musculos estriados, enunciou e documentou duas leis, as chamadas Leis do coração, e que indicam como o coração compensa os superesforços a que fica sujeito nas varias contingencias da vida.

A primeira lei mostra a maneira pela qual o coração reage a um aumento das resistencias perifericas. 0 coração reage aos superesforços dependentes de um acrescimo das resistencias perifericas por um aumento do enchimento diastolico e portanto do rendimento sistólico e por uma diminuição do numero de batimentos, ficando inalterado o volume minuto.

A segunda denominada "Lei dos rendimentos parciais", poderia ser enunciada da seguinte maneira: - A força propulsiva do coração depende do gráu do enchimento diastólico, ou melhor da distenção de suas fibras.

Estas 2 leis são facilmente demonstradas pela preparação cardio-pulmonar de Starling.

$\mathrm{Na}$ clínica, encontramos ocorrencias patologicas que demonstram á saciedade quão verdadeiras são estas duas leis.

(•) Aula proferlda no Curso de Clinica medica da cadeira do prof. Rublac Melra em 27-8-936. 
Vio cnun de um aumento súbito das resistencias periféricas, (crise vascular ;eral, nefrite difusa aguda, etc.) o coração diminue a frequencin. tornn-se bradicardico, para conseguir compensar a alteraçáo viscular. O aumento da diastole favorce? " enchimento ventricular superdistendendo esta cavidade durante a fase diastólica para assim conseguir vencer a resistencia periférica aumentada.

Si o enchimento diastolico ventricular não se realisa de modo satisfatório diminue a força propulsiva ventricular. $\mathrm{E}$ - o que verificamos nos batimentos prematuros onde a energin da sistole ventricular é tĭo diminuida, em certos casos, que núo consegue vencer a resistencia da aorta tornando a sistole ventricular ineficiente.

Estes fatos clinicos podem ser demonstrados pela experimentação com a conhecidissima preparação cárdio- pulmonar e onde com dispositivos especiais pode-se aumentar ou diminuir a resistencia periférica e alterar o enchimento diastolico ventricular e a seguir estudar a potencia da força propulsiva.

Ainda para estudar o mecanismo regulador das alteraçōes hemodinâmicas i necessário não esquecer que o musculo cardiaco está sujcito a lei do tudo ou nada de Bowditch. Por esta lei sabemos que o coração reage sempre pelo maximo de sua capacidade contractil.

Conhecidas estas noções basicas vejamos a maneira do coração se comportar frente a uma alteração que traga um aumento da resistencia a jusante, como por exemplo um aumento de pressão na aorta.

Estabelecido o obstaculo á corrente, as primeiras sistoles ventriculares não conseguirão um rendimento sistólico util, pois a potencia de contração ventricular será insuficiente para vencer a resistencia aortica e o defluvio sistólico será prejudicado, por encurtamento do periodo de defluvio reduzido. Nestas condições restará um residuo pós-sistólico. Estabelecendo-se a diastole cardiaca, o ventriculo se encherá demasiadamente visto adicionar-se ao rendimento auricular habitual ainda o residuo sistolico que restou da contracção anterior. Sobrevirá assim a superdistenção ventricular, que aumentará seguidamente em cada contração cardiaca alé atingir um ótimo, a saber, quando o ventrículo te. nha adquirido uma potència de contração suficiente a vencer o chstáculo aórtico e esvasiar-se completamente. Veremos assim a grande importancia que tem para o mecanismo 
regulador o residuo pós-sistólico que agirá como o excitante natural da energia contratil dos ventriculos.

Si o obstáculo permanece inalterado manter-se-á a superdistenção diastolica que acarretará "a fortiori" una dilatação, chamada compensadora, ativa ou tonogênica quc: se mantendo produzirá a hipertrofia da musculatura ventricular.

Quando a alteração hemodinâmica é condicionada por uma maior oferta de sangue aos ventriculos, como no caso de exercicio muscular, sobrevirá tambem um aumento do enchimento diastólico, que no caso será necessario para umn maior suplencia de oxigenio aos tecidos. Esta superdistensão diastolica se manterá até que não mais seja preciso esta maior oferta de sangue. Ainda neste caso devemos contar com a dilatação seguida de hipertrofia compensadora unıa vez a alteração hemodinâmica permaneça tompo mais ou menos longo.

Resumindo os fatos retroexpostos vemos que a muscu latura cardíaca não difere da estriada comum no modo de reagir ao supertrabalho, isto $\dot{e}$, estabelece-se primeiro a superdistensão, o alonganento das fibras, e só posteriormente é que se instala a hipertrofia.

Si, porém, para a musculatura estriada comum observase que a hipertrofia é verdadeiramente compensadora, não perdendo o músculo com o alongamento nenhuma de suas propriedades fundamentais, para o miocárdio tal fato não existe. A hipertrofia miocárdica não é compensadora pois o musculo desde então trabalhará mais próximo do máximo de esforçc de que é capaz, não ha aumento proporcional da força de reserva, e deste modo quanto mais cresce a hipertrofia tanto mais próximo da fadiga trabalhará o miocárdio, visto estar sujeito a lei do tudo ou nada. Além do que os autores demonstraramı que a circulação do miocardio hipertrofiado é deficiente uma vez que as coronarias não aumentam em número e nem em diametro.

Conhecidas estas nocôes fundamentais de fisio-patologia do miocardio, poderemos abordar o assunto enunciado isto é, distúrbios hemodinâmicos dos vicios valvulares.

Estenose aórtica: - 0 obstáculo tanto poderá estar locallsado no anel valvular conıo no tronco, pois o prejuizo hemcdinâmico será c mesmo.

Estabelecido o obstaculo a jusante dos ventrículos, so- 
brevirả a estasce, islo é, o residuo pós-sistólico, visto a forçn propulsiva ventricular nüo ser suficientemente forte para vencer a resistencia. Alterado o esvasiamento sistólico, inslalado o residluo pós-sistólico, sobrevirá a superdistensão diastólica que será o excitante natural da musculatura ventricular para aumentar a potencia de sua contração até compensar o aumento da resistencia a jusantc. Instala-se assim a dilataçào e postcriormente a hipertrofia.

Si procurarmos estudar as fazes da revolução cardíaca, vamos observar um aumento evidente dos periodos de conIraçao isométrica e de defluvio, o que condiciona o chamado "pulsus lardus" - diminuição na unidade de tempo do rendimento sistólico e alongamento do periodo de defluvio.

Para o acaso particular da estenose aortica poderiamos dizer que é a lesão valvular que traz a maior dilatação $c$ hipertrofia.

Insuficiència aorlica: - Por muito tempo dominou a noção de que a regurgitação de sangue da aorta para o ventrículo nas fases diastólicas era em quatidade ponderavel. As experimentações de Stewart e de Wiggers demonstraram no cão que há nuito mais regurgitação de pressão do que propriamente de sangue, e isto graças a um princípio de fisica. Si dois recipientes inelásticos e cheios do liquido com pressões diferentes, fôrem ligados um ao outro por um tubo dotado de um interruptor de corrente, quando se estabelece o livre transito atravez esta passagem, notaremos que haverá um equili\}, iio de pressão entre os dois recipientes, sem, entretanto, observamos passagem do líquido de um para outro.

E baseado $\mathrm{em}$ tal principio e nos resultados das experimentações que os dois autores citados admitem que há mais um refluxo de pressão que de sangue. Entretanto o simile não é perfeito visto a parede ventricular ser distensivel nas primeiras fazes da diastole. Deste modo teremos que admitir um pequeno refuxo de sangue para a cavidade ventricular.

0 refluxo de sangue que ocorre nas primeiras fazes da diástole e o refuxo de pressão que se realisa durante um periodo de tempo maior, condicionam um aumento da tonicidade ventricular condição indispensavel para a luta contra a sua distensão diastólica, fato prejudicial. Estabelece-se - assim a dilatação tonogênica seguida de hipertrofia compensadora. 
Compreendendo-se bem a pertubação hemodinâmica da insuficiencia aortica torna-se claro porque encontramos com grande frequencia uma evidente diminuição da pressão minima, que é a expressão do refluxo de pressão da aorta para $o$ interior da cavidade ventricular.

A insuficiencia valvular não pode ser muito intensa, pois a experimentação demonstrou que si a abertura do orificio atinge a $83 \%$ é incompativel com a vida.

0 aumento de trabalho da musculatura ventricular é evidente mesmo em pequenas insuficiencias. Assim a experimentação demostrou que a insuficiencia atingindo a $10 \%$ do orificio o trabalho ventricular fica acrescido de $2 / 5$ a $3 / 5$. Si a insuficiencia atinge a $20 \%$ o aumento de trabalho seria de 2 a 5 vezes.

Estenose mitral: - Na estenose mitral estabelecendose um obstáculo a livre passagem de sangue da auricula esquerda pára o ventriculo, sobrevirá estase auricular que trará dilatação e hipertrofia. Como a musculatura auricular é muito pouco potente, a dilatação será muito maior que o gráu de hipertrofia e a estase reinante na auricula cedo repercutirá nas veias e na arteria pulmonar, e por ultimo sobre o ventriculo direito.

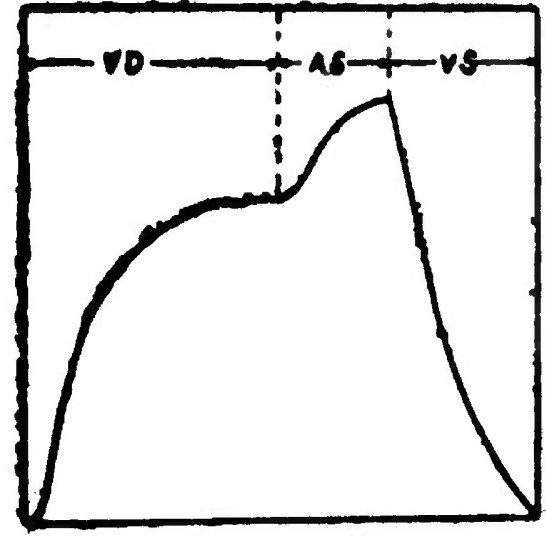

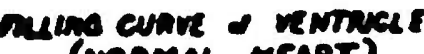
(MOAMA MEAAT)

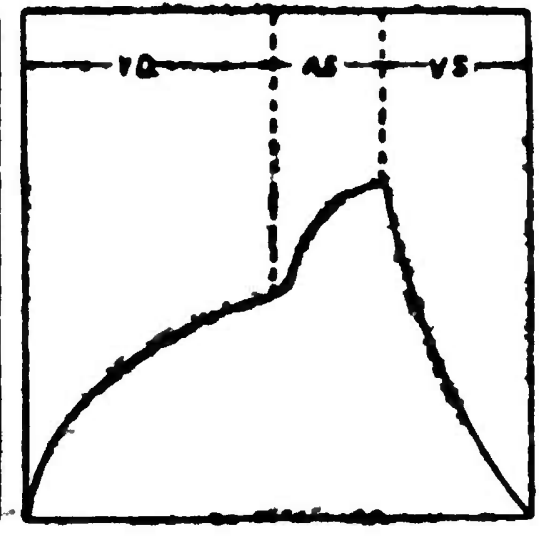

sums cunc mince stanose (a) aremes a ring ?

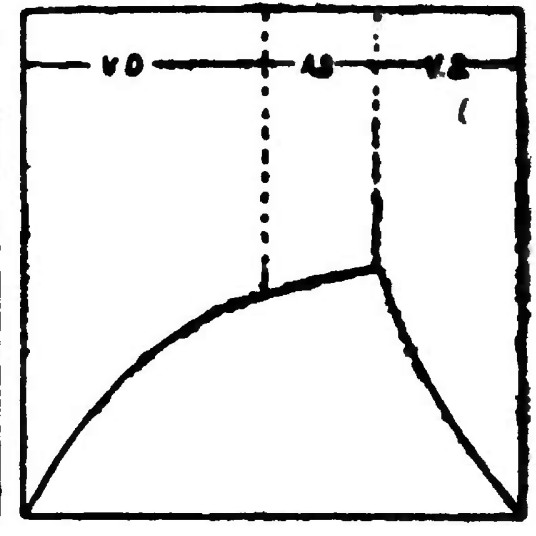

alung cuave mran grenom (a menuarion)

(A. Kerkhof, Am. Heart J., vol. II, n. 2, pag. 206). V. D. destole ventrleninrs

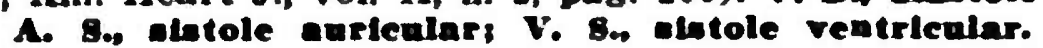

Estábelece-se assim a pressão retrogada na pequena circulação com estase pulmonar mais ou menos evidente.

A difficuldade a livre passagem de sangue da auricula para o ventriculo poderá, quando intensa, alterar a frequencia do coraçāo, tornando-o mais taquicardico, com o fim de 
manter o mesmo volume minuto, visto que o rendimento suntólico pode diminuir.

O enquema de Kerkhof mostra a variação que sofre o cuchimento ventricular guando se instala a estenose da mitral e por último quando sobrevem a fibrilaçũo auricular.

Quanto maior o obstaculo, tanto mais importancin adquire a sistole auricular para a repleção diastolica dos ventriculos. Este super-esforço mais ou menos permanente. dos auriculas explica a frequencia do aparecimento da ribrilaçio auricular neste vicio oro-valvular. Estabelecendose a Rbrilaçảo auricular, o vicio hemodinámico torna-se. ainda mais grave, diminuindo ainda mais o rendimento silólico, pois segundo verificação de varios autores o volume minuto pode cair de $20 \%$. Isto explica a grande limitação para utividade muscular de individuos com estenose mitral Intuis fibrilação duricular.

Esta verificação é facil de ser realisada no homem. Presente a fibrilação auricular e uma vez desaparecidos todos os sinais de insuficiencia congestiva, determina-se o volume minuto. Posteriormente com o uso da quinidina restabelece-se o ritmo sinusal e determina-se novamente o volume minuto. Nestas circustancias nota-se um aumento de $30 \%$ que é o contigente que a sistole auricular concorre para a repleção ventricular.

Aumentando a estase auricular e a dos vasos pulmonares sobrevirá uma superfunção para o V: D. que reagirá a este aumento de pressão por unina dilatação (Lei de Starling) e consequente hipertrofia uma vez o obstaculo seja permanente.

A pressão retrogara mantendo-se sobrevem uma dilatução da via de, saida do V. D. e por último tambem a dilatação da via de entrada com insuficiencia do orificio tricuspide seguida de estase auricular e por ultimo estase venosa que é a expressão maxima da insuficiencia cardiaca congestiva ou da insuficiencia ventricular direita dos francezes.

Insuficiencia mitral: - Deixamos para uma aula proxima a discussão, sempre interessante, e cada vez mais com:licada, do problema da insuficiencia mitral. Cuidaremos apenas de estudar a alteração hemodinâmica que sobrevirá para o coraçio uma vez se instale uma insuficiencia do orificio $A-V$ esquerdo. 
Os classicos admitiam que na insuficiencia mitral havia um aumento da pressão auricular devido a pressão retrofada condicionada pelo refluxo de sangue do ventriculo para a auricula.

Wiggers e Staub realisando experimentação no coração do cão nos quais produziam extensas lesōes valvulares e até mesmo extirpação completa da valvula não verificarṇn, aumento da pressũo intra-auricular pelo que negaram an, conclusões dos classicos. Wiggers poude ainda documentar que a fase de contração isométrica ventricular não $: \because$ alterava continuando a se processar no mesmo espaço $i$ : lempo. Entretanto no periodo de defluvio passará menos sangue para a aorta estabelecendo-se uına quéda do volume minuto devido a passagem do sangue para a auricula. Disto resultará um maior enchimento ventricular na fase diastólica com aumento da tensão diastólica e mais enchimento ventricular (Lei de Starling) para restaurar a descarga e equilibrar o volume minuto. No coração do cão, este equilibrio se processa em poucos batimentos. Assim para Wiggers a compensação se realisa a custa do aumento do V.E., sem qualquer interferencia na pequena circulação.

Edens não acha razoavel transportar para o homem as verificações realisadas no coração do cão, uma vez que o musculo é são e a experiencia se realisa em condições hemodinâmicas diferentes, isto é, com o torax aberto.

Edens ainda lança mão dos argumentos clinicos que demostram o sofrimento precoce do V. D. nas alterações do V. E.

Para este autor a compensação na insuficiencia mitral se estabelecerá graças a uma alteraçào na duração dos periodos de contração isométrica e de defluvio que devem ser muito rápidos para evitar a regurgitação para a auricula. Estabelecendo-se a insuficiencia mitral haveria refluxo de sangue do ventriculo para a auricula e disto resultará um aumento do enchimento diastólico ventricular. Graças a este aumento do enchimento inicial que causa a distenssão das fibras miocardicas resultará uma maior capacidade do ventriculo para lançar o sangue na aorta partindo de uma pressão inicial baixa. Este aumento do enchimento pernitirá uma contrnção mais potente e mais rapida diminuincio as fases de contração isométrica e principalmente a de 
defluvio com o fim de evitar, o mais possivel, refluxo de sangue para a auricula.

Admitindo tal mecanismo compensador haveria na insuficiencia mitral uma dilatação e hipertrofia do ventriculo esquerdo, e enquanto esta cavidade fosse capaz de compensar a alteração hemodinâmica não se alteraria a circulação pulmonar e não haveria a influencia má da pressão retrogada sobre o ventriculo direito. 